\title{
Biguanides: A new potential therapeutic option for pituitary tumors?
}

Ma Carmen Vázquez-Borrego $^{1}$, Antonio C. Fuentes-Fayos ${ }^{1}$, Alejandro Ibáñez-Costa ${ }^{1}$, Eva Venegas-Moreno ${ }^{2}$, M $^{a}$ Ángeles Gálvez ${ }^{3}$, Alfonso Soto-Moreno ${ }^{2}$, Rhonda D. Kineman ${ }^{4}$, Justo P. Castaño ${ }^{1}$, Raúl M. Luque ${ }^{1}$

'Department of Cell Biology, Physiology and Immunology, University of Córdoba (UCO); Hospital Universitario Reina Sofía (HURS); Instituto Maimónides de Investigación Biomédica de Córdoba (IMIBIC); CIBERobn and ceiA3, Córdoba, Spain; ${ }^{2}$ Metabolism and Nutrition Unit, Hospital Virgen del Rocío; Instituto de Biomedicina de Sevilla Sevilla (IBIS); 35ervice of Endocrinology and Nutrition, HURS/IMIBIC

Research and Development Division, Jesse Brown Veterans Affairs Medical Center and Department of Medicine, Section of Endocrinology, Diabetes and Metabolism, University of Illinois at Chicago, Chicago, IL, 60612.

Introduction

Pituitary adenomas (PA) comprise a commonly underestimated pathology in terms of incidence and associated morbimortality. Somatostatin analogs and dopamine antagonists constitute the main medical treatments for PA. However, an appreciable subset of patients are resistant or poorly responsive to these drugs, and hence, the search for new therapies to control tumor growth and/or hormone secretion is crucial. Biguanides such as metformin (MF; commonly used to treat type-2 diabetes), phenformin (PF) and buformin (BF) have been shown to exert antitumoral actions in different tumor types (brain tumors, prostate, breast and lung cancers) but their actions in PA cells have not been reported.

The AIM of this study was to determine the effect of these biguanides on key functional parameters (hormone expression and secretion, gene expression of key modulators of pituitary cell function and signaling pathways) and on cell viability in normal and/or tumoral pituitary cell cultures and cell lines.
Materials \& Methods

(1) Papio anubis

pituitary

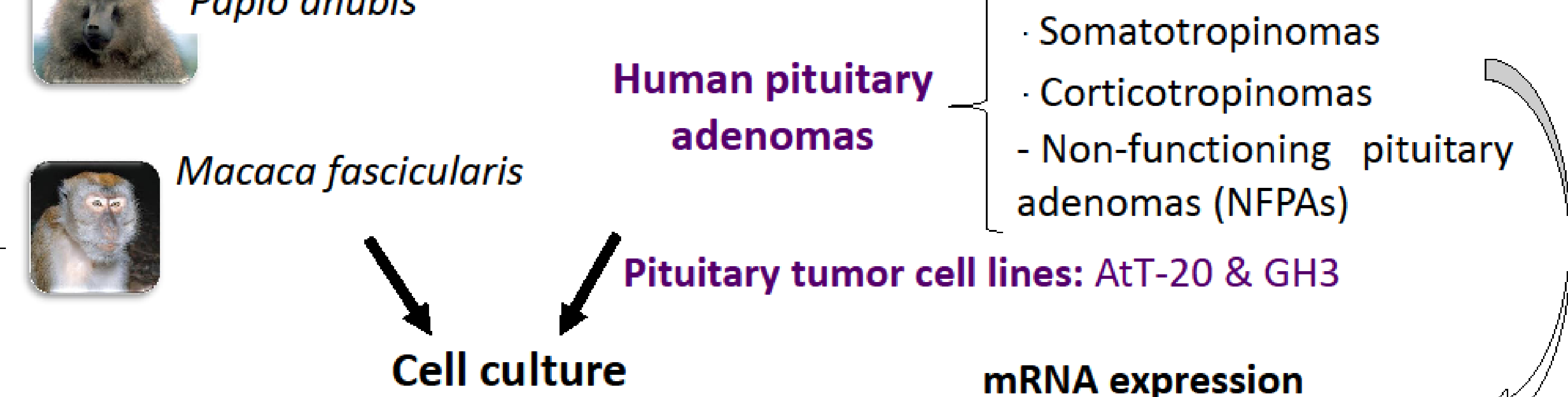

Cell culture

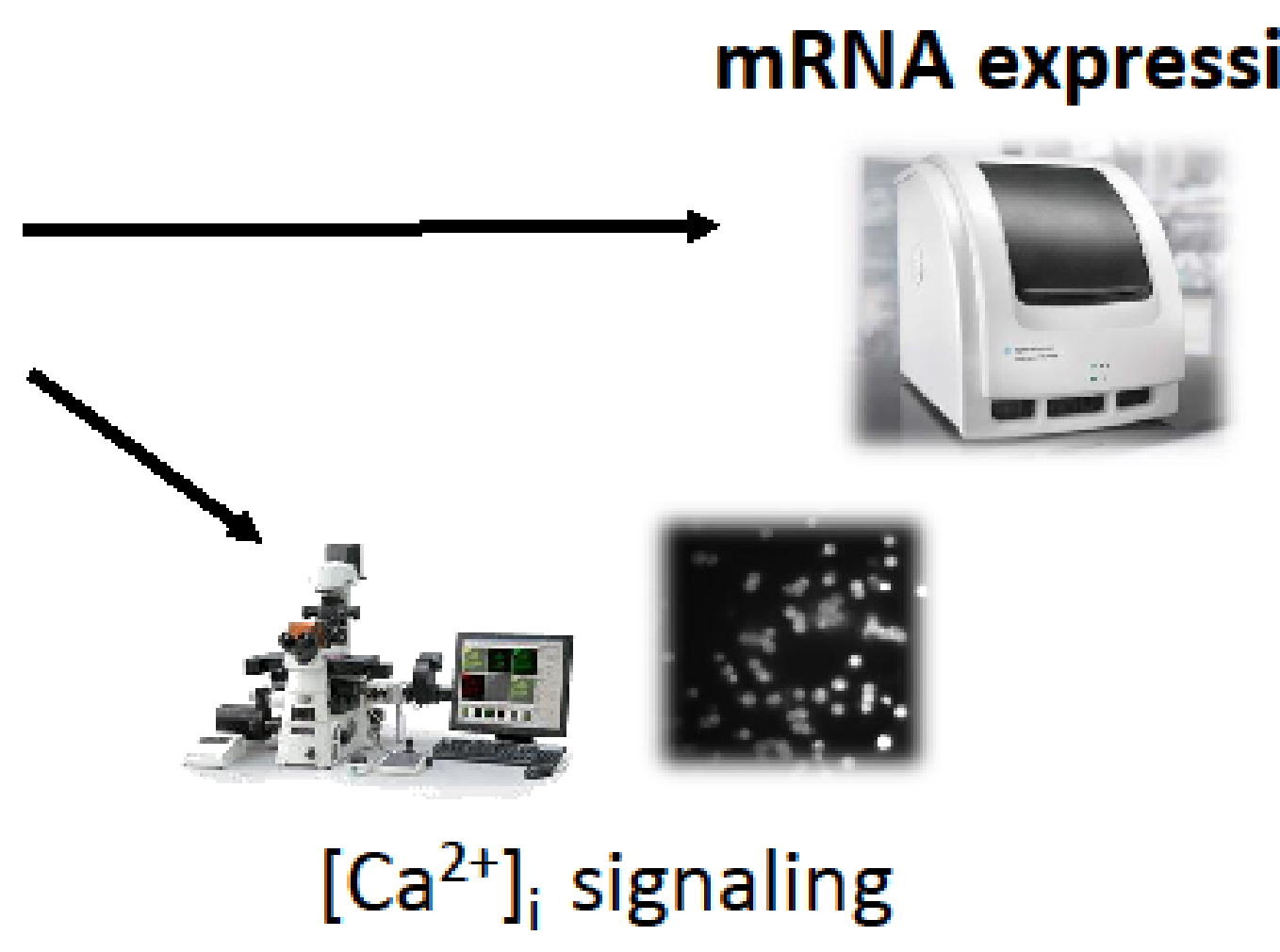

CELL VIABILITY

Corticotropinomas AtT-20 cell line

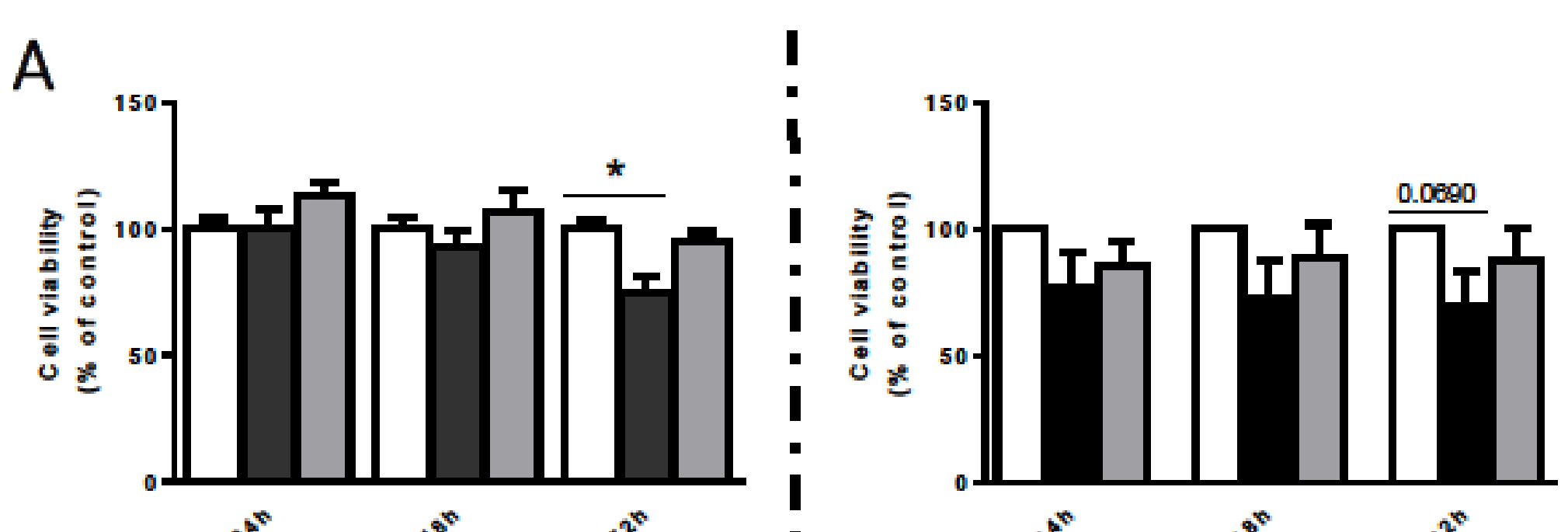

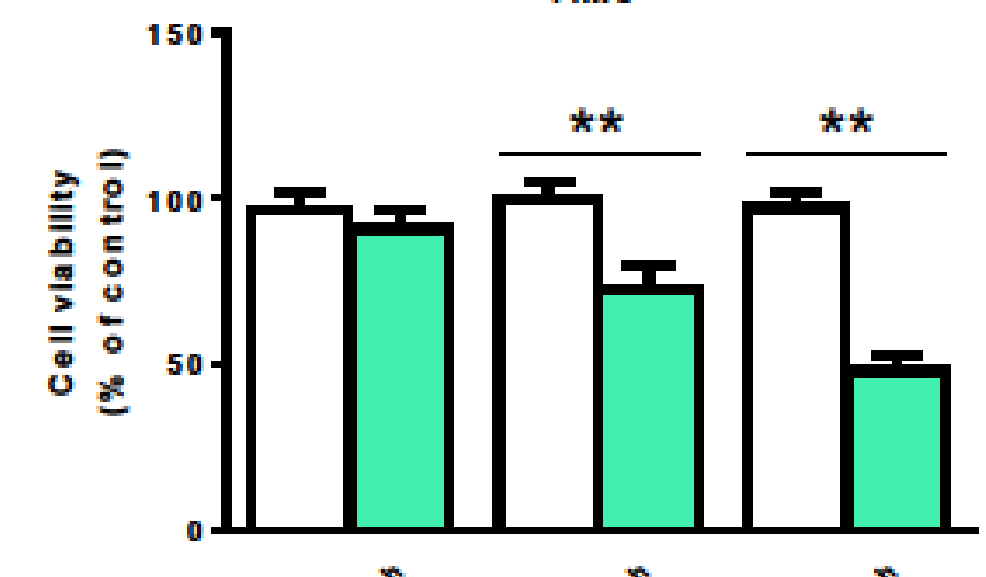
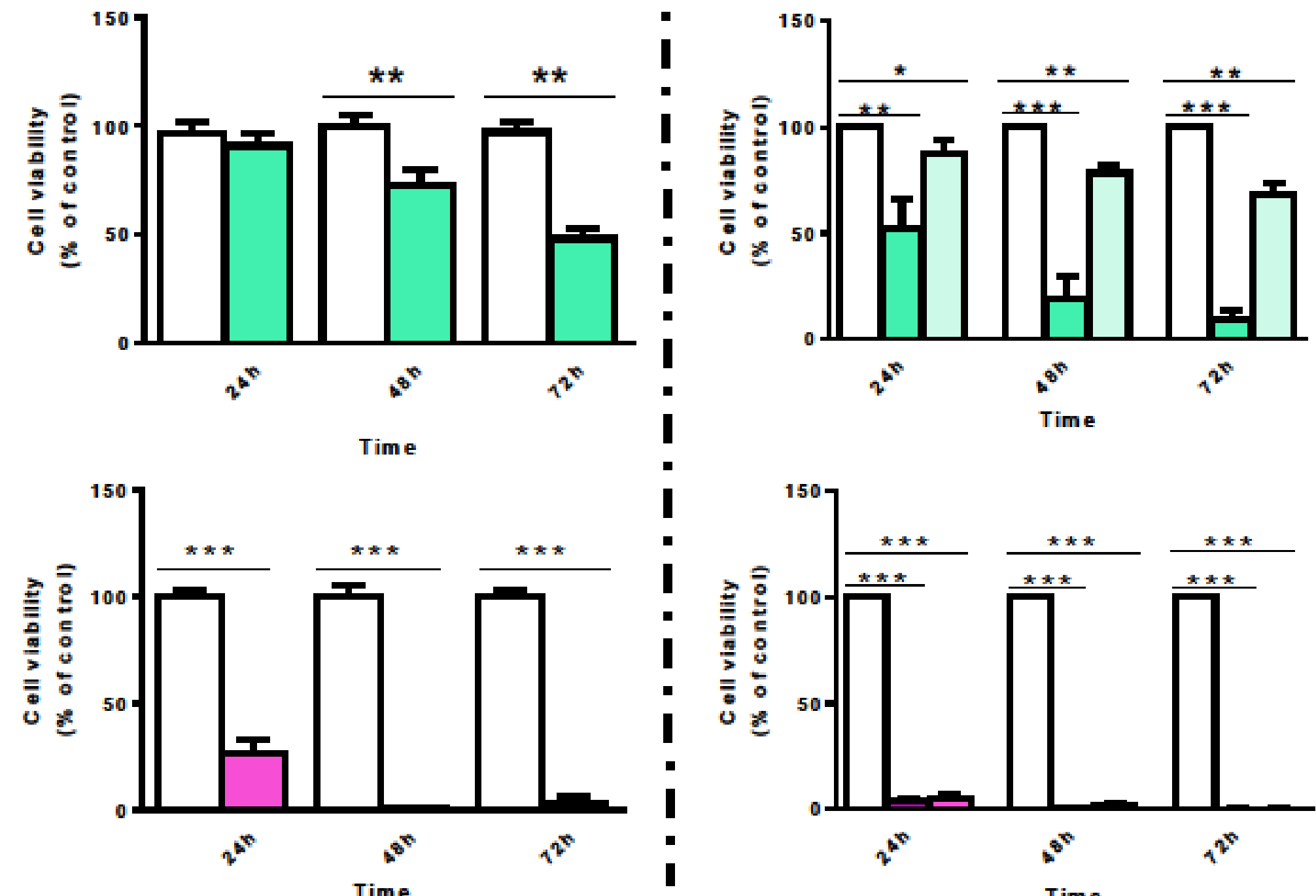

\section{Results}

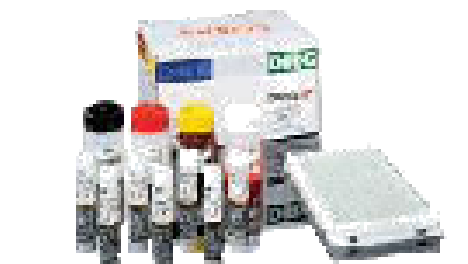

Hyta

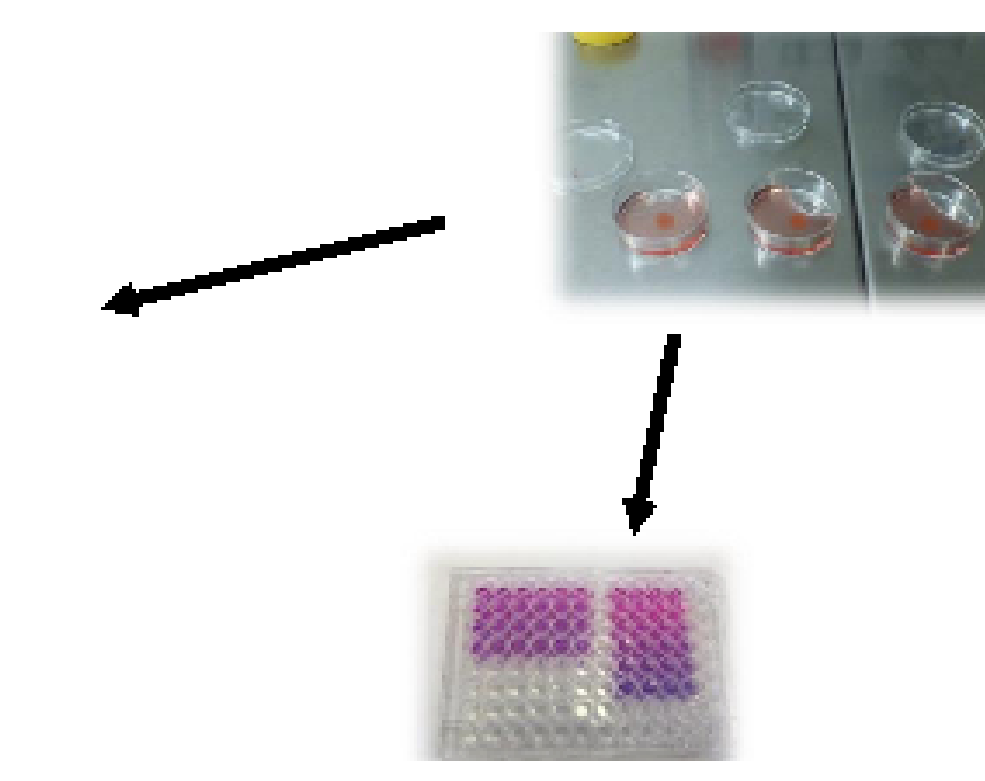

Cell viability
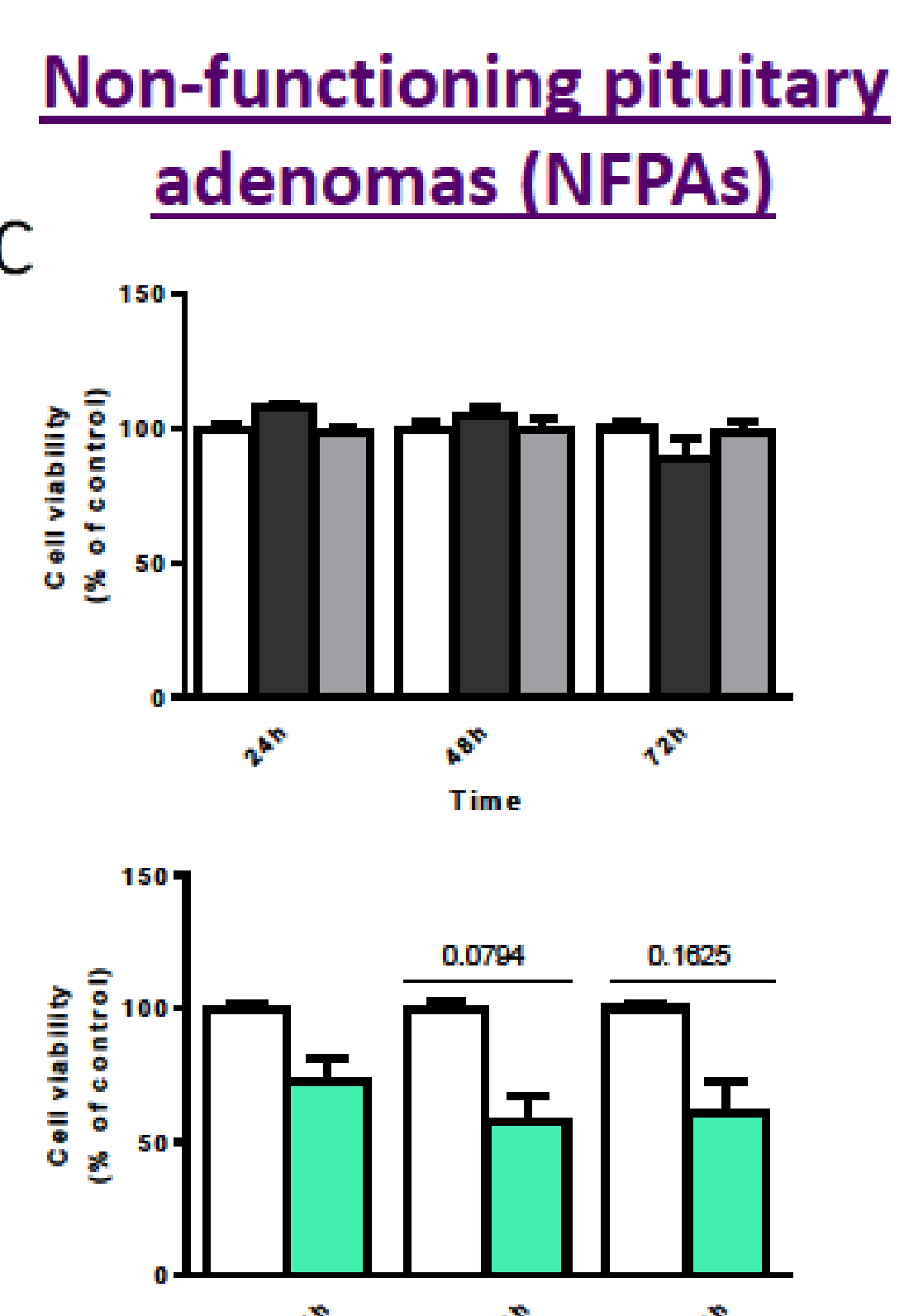

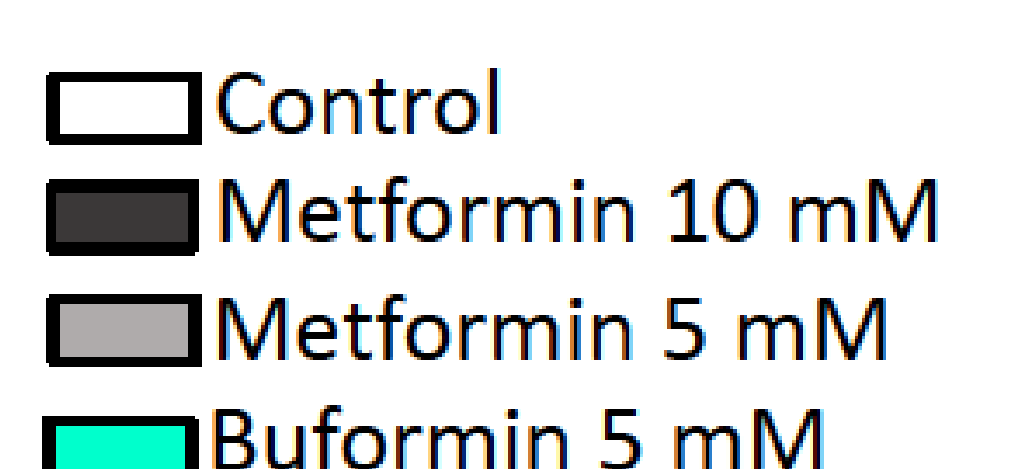

Buformin $5 \mathrm{mM}$ $\square$ Buformin $2 \mathrm{mM}$ Phenformin $5 \mathrm{mM}$ $\square$ Phenformin $2 \mathrm{mM}$

Treatment with different biguanides, especially with phenformin and buformin, was able to reduce cell viability in a dose-dependent manner in different pituitary adenomas subtypes, including corticotropinomas, somatotropinomas and nonfunctioning pituitary adenomas.

Similar results were obtained in pituitary ACTHand GH-secreting tumors derived cell lines.

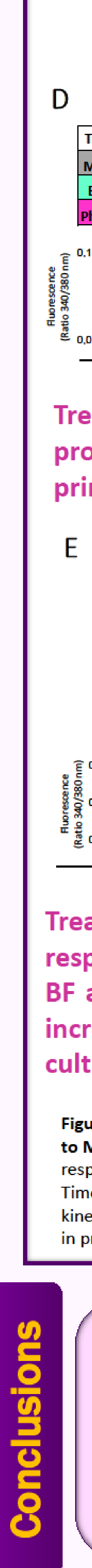

$\left[\mathrm{Ca}^{2+}\right]_{i}$ KINETIC Corticotropinomas

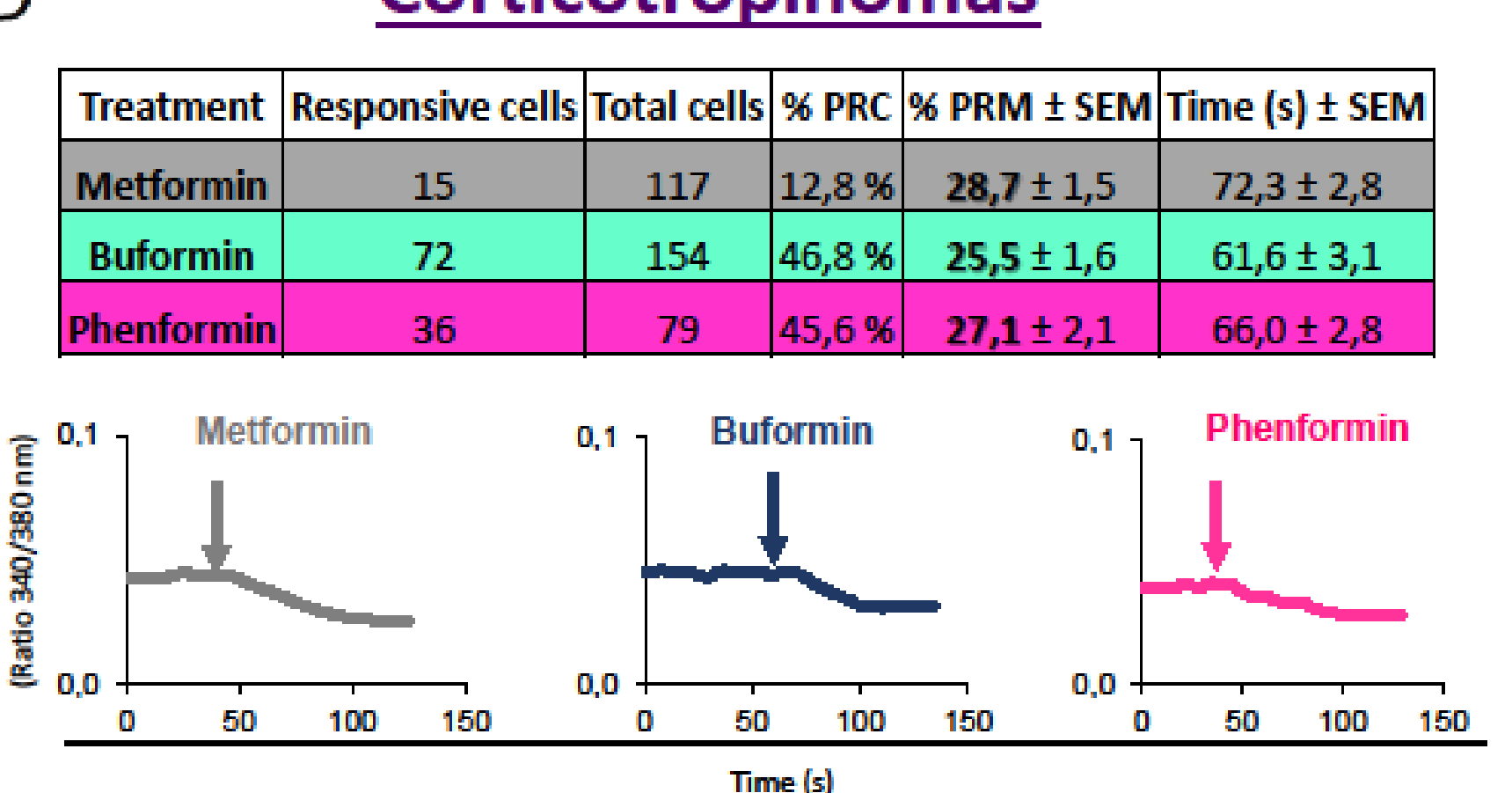

Treatment with different biguanides produced a decrease of $\left[\mathrm{Ca}^{2+}\right]_{\mathrm{i}}$ levels in primary corticotropinoma cell cultures,

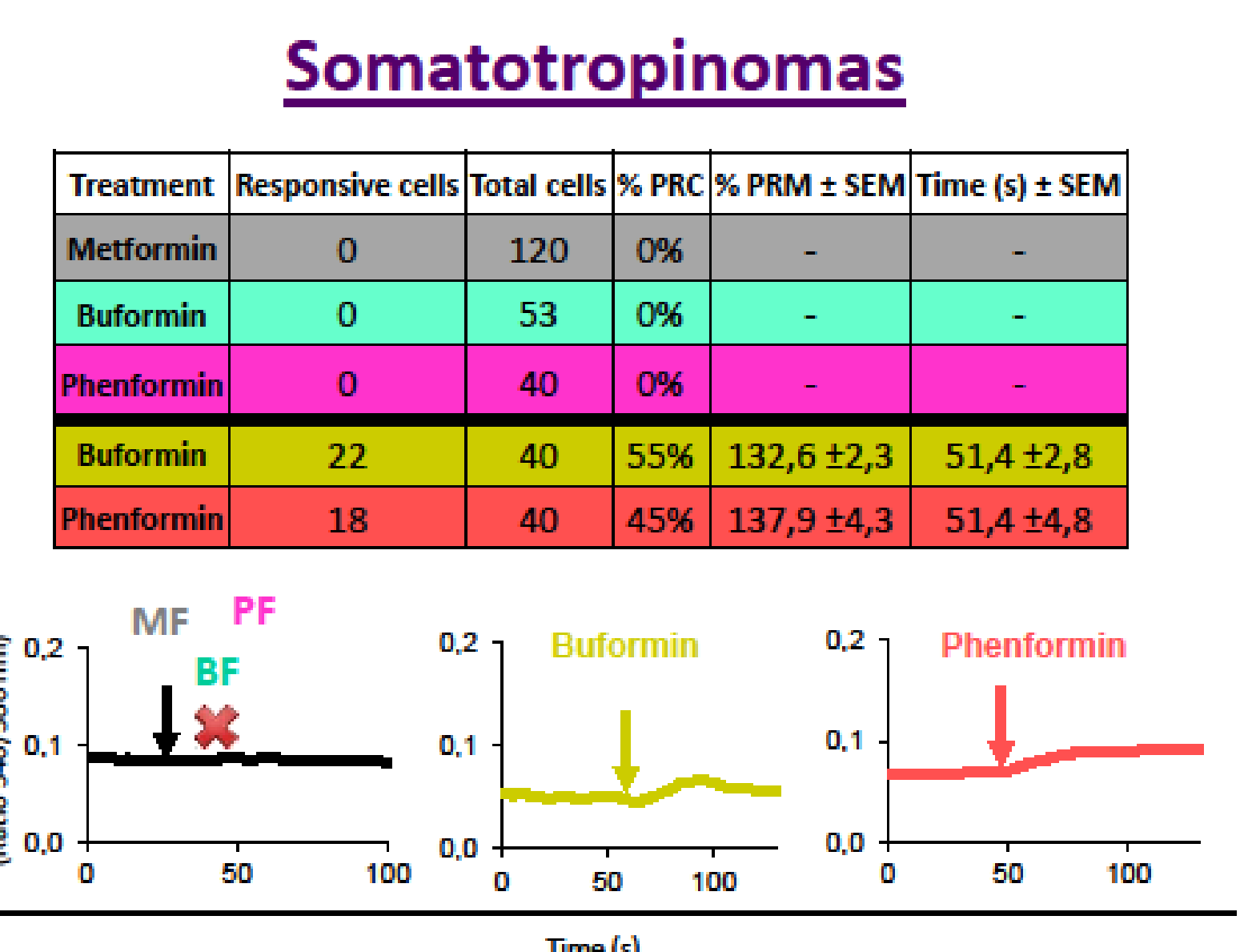

Treatment with MF did not elicit any esponse in $\left[\mathrm{Ca}^{2+}\right]_{\mathrm{i}}$ levels but, surprisingly, and PF treatment elicited a paradoxical ine on $\mathrm{Ca}^{2+}{ }^{2+}$, levels in a subset of ultured somatotropinoma cells.

sese 2 Results from cytosolic calcium kinetic assays in response
$\mathrm{MF}, \mathrm{BF}$ and $\mathrm{PF}(5 \mathrm{mM})$. PRC (\%): percentage of responsive cells in ponsive samples. PRM (\%): percentage of maximum response.

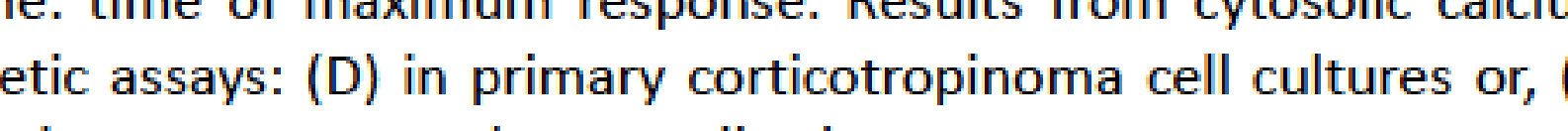

1. Different biguanides are able to significantly decrease cell viability in tumoral, but not normal, pituitary cells in a dose- and cell type-dependent manner, through a mechanism that could involve calcium mobilization.

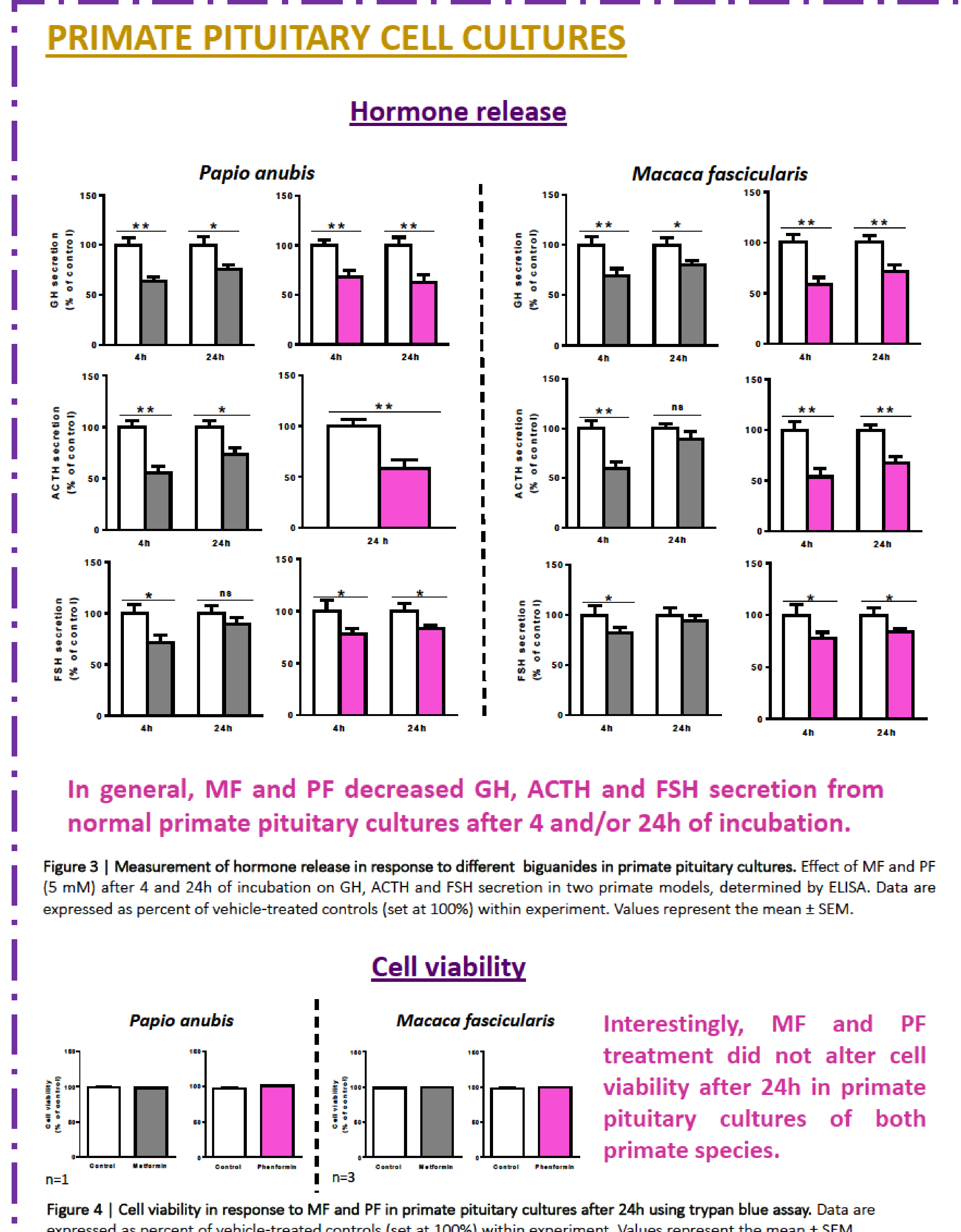

Figure 1 I Cell viability in response to metformin (MF), buformin (BF) and
phenformin (PPF). (A) Effect of $\mathrm{MF}(5$ and $10 \mathrm{mM}), \mathrm{BF}$ and PF $(5$ and $2 \mathrm{mM})$
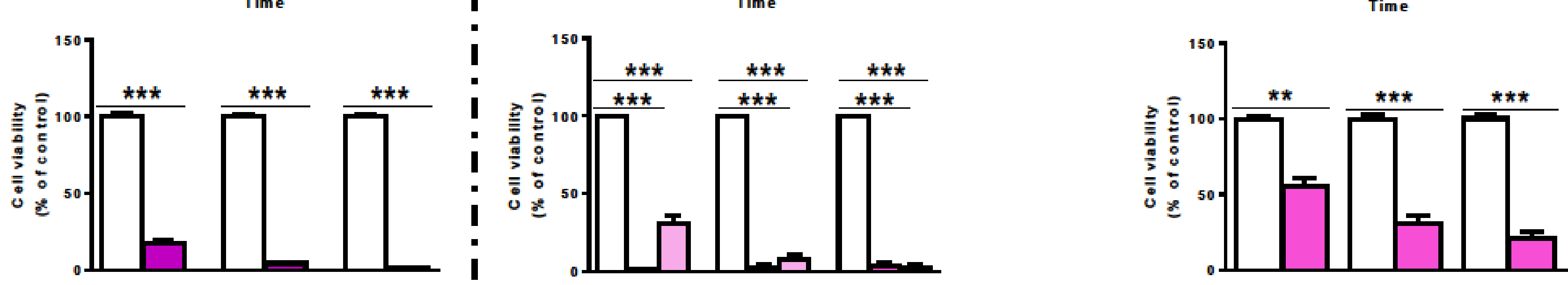

(n=5) and AtT-20 (n=7); (B) somatotropinomas $(n=2)$ and $G H 3$ cell line $(n=4)$

(C) NFPAS $(n=4)$. Data are expressed as percent of vehicl-e-treated co
(set at 100\%) within experiment. Values represent the mean \pm SEM.

mRNA expression in Papio anubis

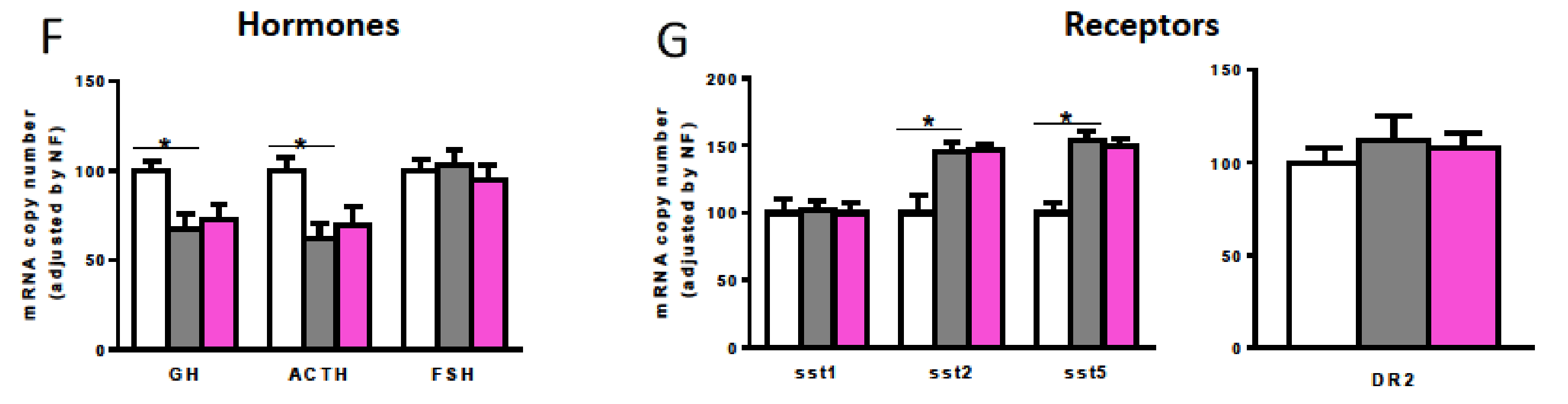

MF and PF were able to

significantly decrease GH and

levels in primary pituitary cell

cultures from baboons.

Interestingly, MF and PF also regulated

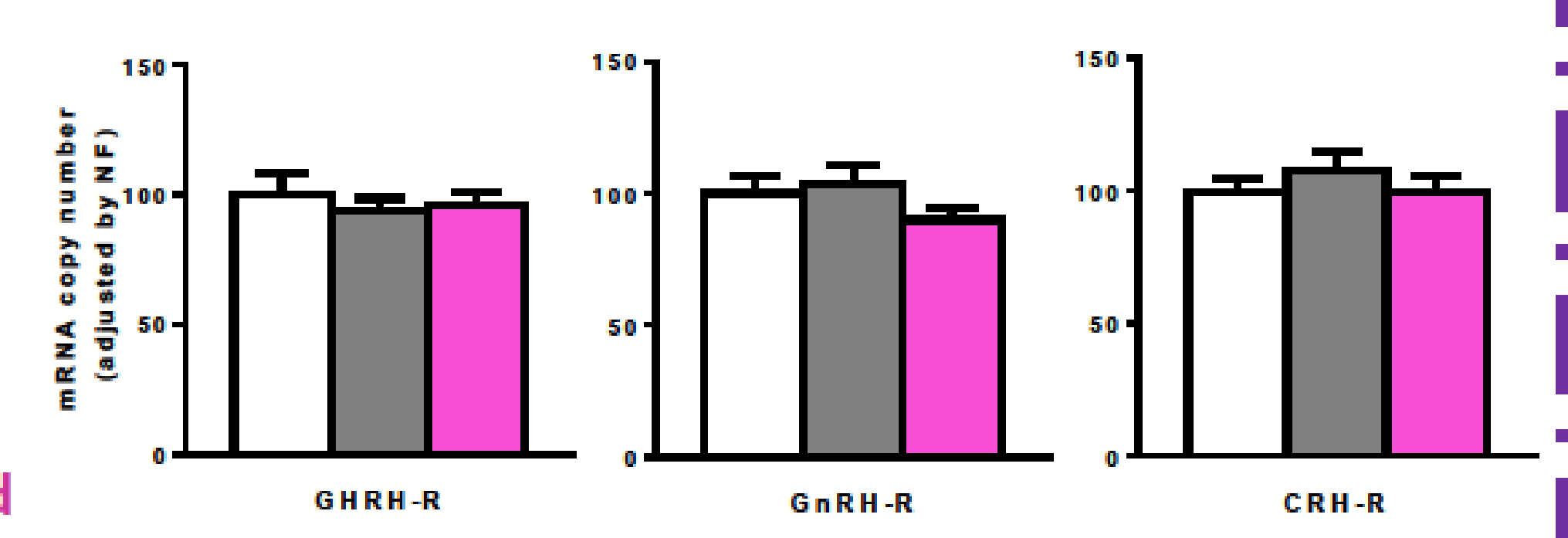
the expression of some key receptors

Specifically, we found that somatostatin

receptor types 2 and 5 as well as insulin

and IGFI receptors were upregulated in

sponse to MF and PF.
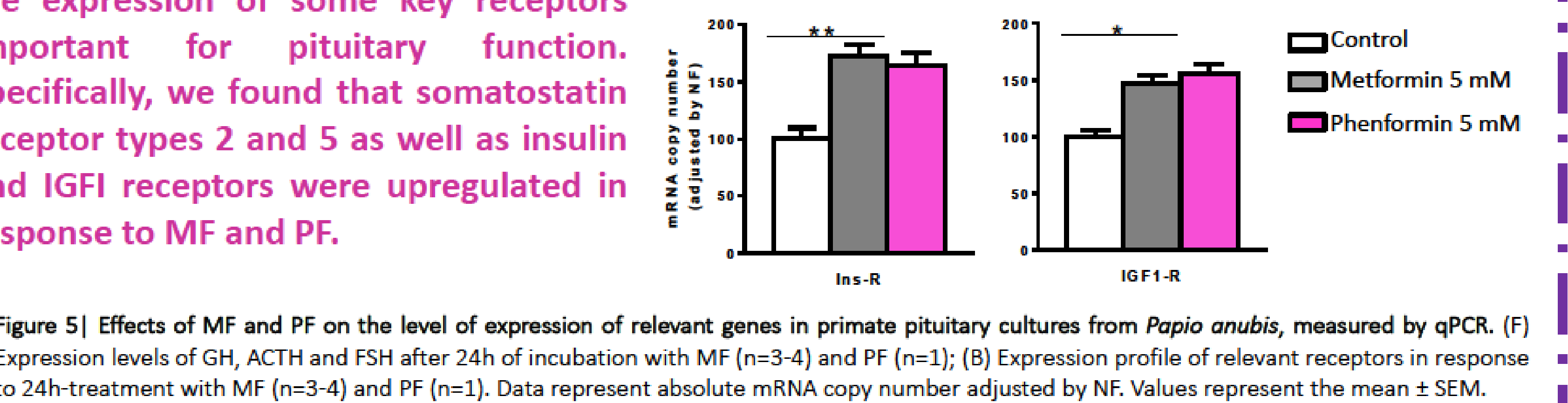

Signalling mechanisms in Papio anubis

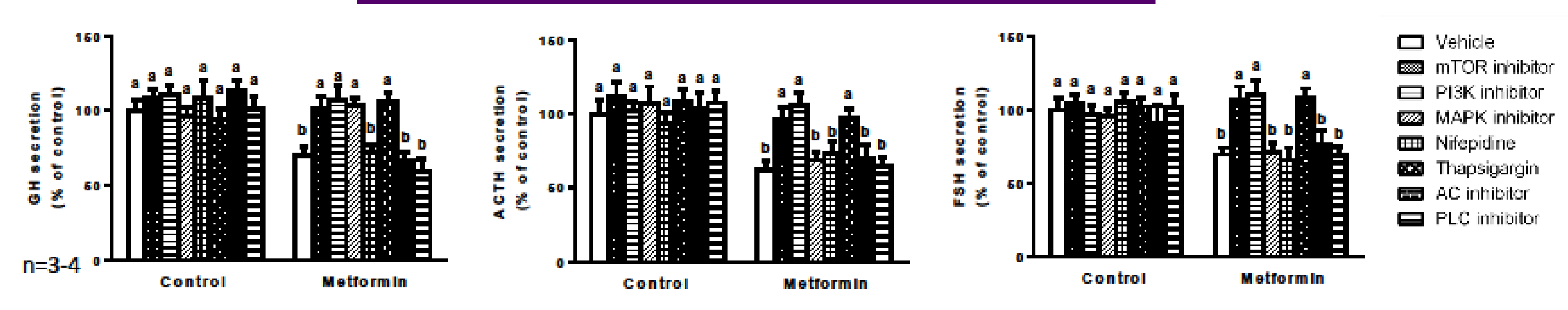

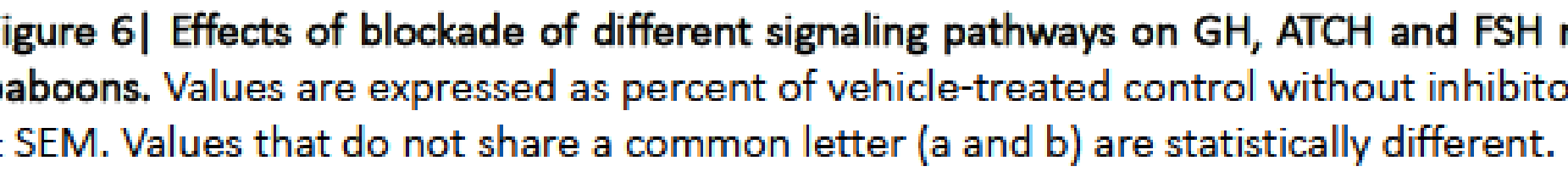

The use of inhibitors of different signalling pathways revealed that the inhibitory effect of metformin on GH, ACTH and FSH release involved the activation of mTOR, PI3K and

cellular calcium signaling. In addition, MAPK pathways were also important for the

intracellular calcium signaling. In addition, MAPK pathways were also important for the
inhibitory effects of MF on GH release but not on ACTH and FSH release.

2. Treatment with MF and PF directly decreases GH, ACTH and FSH expression and/or secretion in normal primary pituitary cell cultures from two primate species (Papio anubis and Macaca fascicularis) through common (mTOR, PI3K and intracellular calcium) and distinct (MAPK) intracellular signaling pathways.
3. The effects of MF and PF in the function of different pituitary cell types from primates also involved the regulation of the expression of key receptors essential in the normal function of these cell types (i.e. sst2, sst5, Ins-R and IGF1-R).
Therefore, given the demonstrated clinical safety of biguanides, our results suggest that these drugs could be used as a potential therapeutic option for the treatment of human pituitary adenomas.
EP855 - Pituitary-Basic Ma Carmen Vázquez Borrego

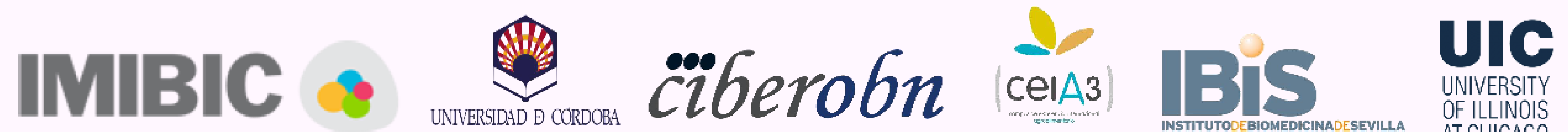

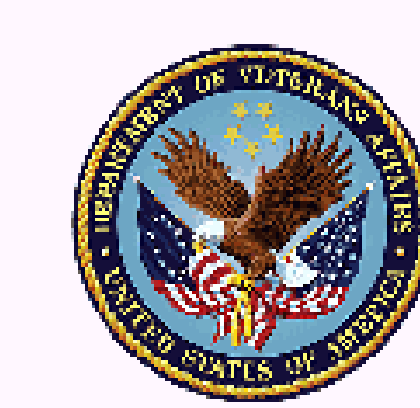

PogtersionOnline 